\title{
The effect of earthquake characteristics on the collapse of historical masonry buildings: case study of the mosque of Takiyya al-Sulaymaniyya
}

\author{
W. Jäger \& T. Bakeer \\ Dresden University of Technology, Chair of Structural Design, Germany
}

\begin{abstract}
Different factors influence the collapse behaviour of masonry structures, and one of the major factors is the characteristics of the earthquake itself. This effect is going to be more complicated for historical constructions, which involve different structure members with different geometries.

The present study focuses on the effect of earthquake characteristics on the collapse behaviour of historical masonry structures. The effect of earthquake direction and the frequency content of the earthquake are discussed. A brief background of the selected case study and modelling process are given first, and the geometry of the whole structure is created where micro modelling strategy is employed. The collapse analysis of the structure is performed under an artificial model based on the earthquake characteristics. Unidirectional earthquakes are applied to the structure from different angels in order to investigate the weakest situation. Finally, different earthquake models are generated with different frequency contents according the soil profiles and applied consequently on the structure to explore the worst situation.
\end{abstract}

Keywords: collapse analysis, historical masonry buildings, earthquake direction, frequency content, artificial accelerogram.

\section{Introduction}

The architecture of historical masonry structures shows a wide disparity through centuries, and the structure members are formed in various geometries (pillars, arches, vaults, domes and minarets). However, the variation in the geometries of 
the structure elements also results in different performances against earthquakes, and their vulnerability to collapse. The study of the behaviour of a single structural element may give an indication about its individual vulnerability for earthquakes. However, the success of such study is associated with considering the other existing structure members that shape the entire geometry. For example, domes are intrinsically much stronger against earthquakes than other members and their possible weakness is essentially associated with the stiffness and strength of the supporting members. In the case of Hagia Sophia, the deformability of the main pillars and supporting arches are caused sometimes by the damage and the collapse (Croci [3]). For these reasons, the collapse of historical masonry structures will be demonstrated throughout a case study of a full masonry structure that comprises the disparities in structure elements (pillars, arches, vaults, domes and minarets). Indeed, many masonry structures exist in the world that have such variety in elements, but those that are in earthquake hazardous regions are more argued for this study.

The good examples of such buildings are conceivably those built by the medieval architect of Ottoman Empire Mimar Sinan. Furthermore, most of those buildings are constructed in regions that experience seismic activity like Turkey, Syria, Greece, Cyprus, Ukraine and Bulgaria. Among the big number of the works of Sinan, the beautiful mosque of Takiyya al-Sulaymaniyya in Damascus, the capital city of Syria, has been chosen for the present study.

\section{Mosque of Takiyya al-Sulaymaniyya}

Takiyya al-Sulaymaniyya is a complex in Damascus, Syria, considered as the most important Ottoman cultural building in the city. It was built by the Sultan Süleyman I or Sulayman al-Qanuni (1520-1566) between 1554 and 1560 (Rihawi [7]). The entire complex was restored in the 1960s by Directorate General of Antiquities of Syria.

The mosque is the largest and the major part of the complex, located on the southern end of the courtyard. The architecture of the mosque is similar to the prototypical forms used by Sinan a cubic mass crowned by a vast hemispherical dome rising over pendentives, with a portico in front, and twin minarets. The hall of the mosque is based on a square plane of 16 by 16 meters. The dome is suited on square of 14.3 by 14.3 meters and rises to a height of 7.4 meters on a circular base supported by four pendentives and four large arches which stand at the corners of the square bases (Figures 1 and 2).

The diameter of the hypothetical sphere which includes both the dome and the pendentives (the diagonal of the square) is about 20.1 meters.

The domes in the interior portico rest on pendentives, Figure 3, whereas the central bay over the mosque entrance is roofed by a vault higher than the domes. The exterior portico is covered by a shed roof. The pointed arches in exterior and interior porticos are braced using steel bars. This kind of bracing system is commonly used in most works of Sinan. 

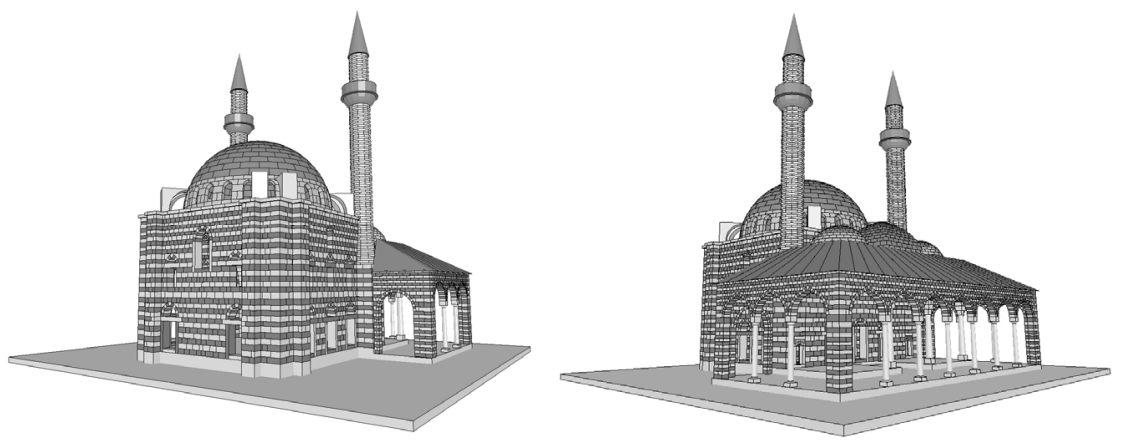

Figure 1: $\quad$ North-east (left) and south-east (right) views for the mosque.

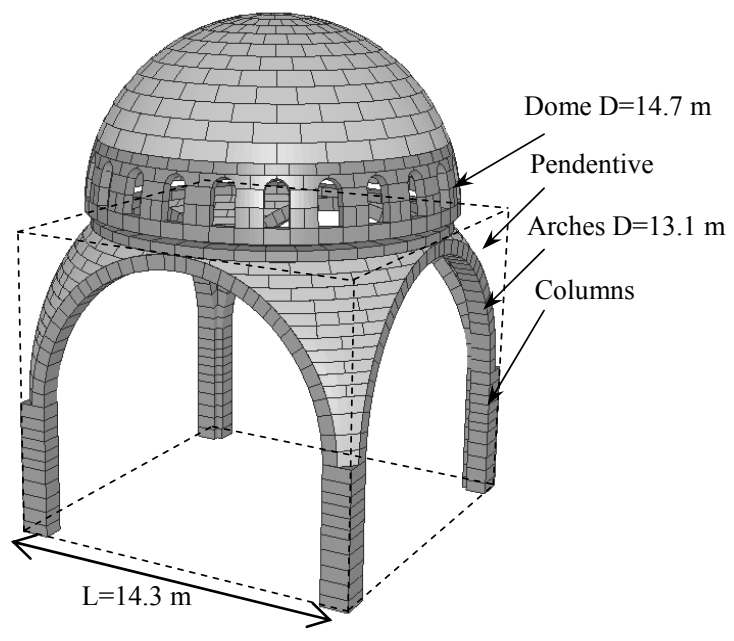

Figure 2: The dome of the mosque supported on pendentives.

The mosque of Takiyya al-Sulaymaniyya has twin high polygonal minarets. The first high storey of the minaret ends with a balcony. The second short storey is $9.4 \mathrm{~m}$ height and covered by typical conical crown, sheltered by lead.

\section{Finite element modelling}

The whole building is modelled in LS-DYNA software stone by stone. The stone cuts are considered in modelling. The mesh of each stone has been generated, so that, stones of simple geometries meshed by $3 \times 3 \times 3$ elements. Finer meshes lead to a large number of elements in the overall structure and courser meshes possibly cause numerical instabilities in contact treatments using LS-DYNA code. Constant stress eight-nodded brick element with a single integration point has been employed with a Flangan-Belytschko stiffness form to control the 


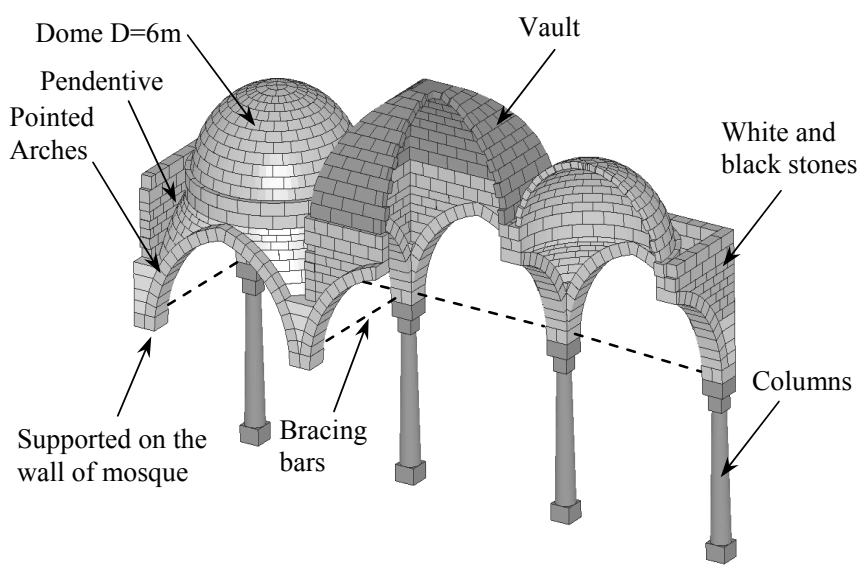

Figure 3: The interior portico in front of the mosque.

hourglass effect (Hallquist [4]). Each part of the structure is created in a separate file that contains the finite elements of this part. Later, the whole parts are assembled in LS-PrePost. Elastic material model is adopted in the following study, due to relatively high materials strength. The elastic material model guarantees a smooth running through the calculation and avoids the termination due to negative volumes which arises with soft materials. Tiebreak contact model is employed to represent the interface between the units. The Tiebreak contact in LS-DYNA allows the modelling of connections which transmits both compressive and tensile forces with optional failure criterion (Bala [2]). The option 6 of contact tiebreak permits damage modelling by scaling the stress components after failure is met. The following yield function is employed:

$$
F(\boldsymbol{\sigma}, \kappa)=\frac{\sigma^{2}}{f_{t}^{2}}+\frac{\tau^{2}}{c^{2}}-\Omega(\kappa)
$$

where $f_{t}$ is the tensile strength of the interface, $c$ is the shear strength of the interface, $\Omega(\kappa)$ is the linear damage function, and given by $\Omega(\kappa)=1-\kappa, \kappa$ damage scalar and given by $\kappa=w / w_{c}$ and $w, w_{c}$ current crack width and crack width at failure, respectively. After the damage is initiated, the stress is linearly scaled down until the crack width reaches the critical distance $w_{c}$ at which the interface failure is complete.

The resultant model is involved with 768887 nodes and 363567 elements. Therefore, parallel processing is adopted. Each calculation is performed using parallel 40 Intel Itanium processors "SGI Altix 4700" in the centre of High Performance Computing of TU-Dresden. The calculation for the model was carried out along 7 days for 20 seconds of loading. 


\section{Earthquake modelling}

In Syria, during the last decades, the region has experienced several destroyable earthquakes, and it is one of the few places worldwide where the historical strong earthquake events are well documented (Sbeinati et al. [9] and Malkawi et al. [5]).

Syrian engineering code provides PGA distribution map for minimum $10 \%$ probability of being exceeded in life time of 50 years which corresponds to return periods of 475 years. This PGA distribution map is used for the design of engineering structures. However, for historical monuments a longer life time up to 200 years must be considered.

Malkawi et al. [5] employed a probabilistic model that able to estimate the probability of occurrence of forthcoming earthquakes in Syria, based on available information on Seismicity, geo-tectonics setting and attenuation characteristics of peak ground acceleration. Several PGA distribution maps are proposed by Malkawi et al. [5] the map of PGA distribution for 10\% probability exceeding in life time 200 years is plotted in Figure 4. In addition to the regional seismicity, further information can be obtained from the design response spectra provided in engineering standards. The spectral analysis of engineering buildings in Syria usually follows the response spectrum provided in UBC97 [11]. The response spectrum in UBC97 [11] is related to the site specific values of $C_{a}$, $C_{v}$ which are given in Table 1.

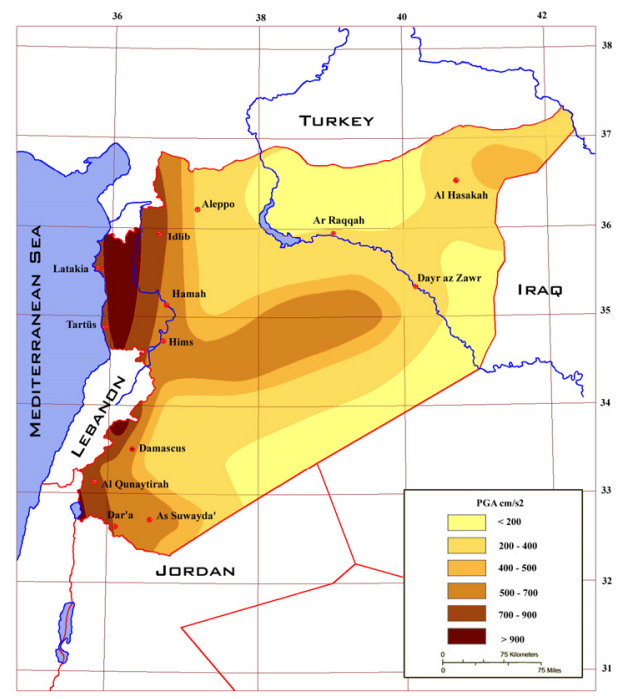

Figure 4: Maximum peak ground acceleration $\left(\mathrm{cm} / \mathrm{sec}^{2}\right)$ with $10 \%$ probability exceeding in a life time of 200 years (return period $=1898$ years). 
Table 1: $\quad$ The values of $C_{a}, C_{v}$ according to the soil type (UBC97 [11]).

\begin{tabular}{|l|l|l|l|l||}
\hline $\begin{array}{l}\text { Soil } \\
\text { Type }\end{array}$ & $\begin{array}{l}\text { Soil profile name/ Generic } \\
\text { description }\end{array}$ & $\begin{array}{l}\text { Share wave } \\
\text { velocity }(\mathrm{m} / \mathrm{sec})\end{array}$ & $C_{a}$ & $C_{v}$ \\
\hline$S_{A}$ & hard rock & $>1500$ & 0.32 & 0.32 \\
\hline$S_{B}$ & rock & 760 to 1500 & 0.40 & 0.40 \\
\hline$S_{C}$ & very dense soil and soft rock & 360 to 760 & 0.40 & 0.56 \\
\hline$S_{D}$ & stiff soil profile & 180 to 360 & 0.44 & 0.64 \\
\hline$S_{E}$ & soft soil profile & $<180$ & 0.36 & 0.96 \\
\hline
\end{tabular}

Since there are no earthquake records for strong intensities, the generation of an artificial one is needed. Many methods proposed in literature to generate the artificial accelerogram for regions that are lacking earthquake records, namely: the sums of harmonic functions, filtering of white noise (Meskouris [6] and Thiele [10]), spectral density model (Rofooei et al. [8]) or finite element modelling of the fault system (Aagaard [1]). The sum of harmonic function method is employed in the following study to generate the artificial accelerograms.

\section{Effect of earthquake characteristics}

The collapse analysis for specific earthquake motion gives very crude estimation for the behaviour of prospective earthquakes. The collapse analysis under the actions could emphasize the weak parts of the structure, but the weak state is also associated with loading conditions. In case of earthquakes, there are high uncertainties. However, several parameters were provided in quantitative form to characterize the random motion of earthquakes that might influence the behaviour of the structure, like Peak ground acceleration and incremental velocities. The frequency content of the ground motion is also of high importance.

In the following, the collapse analysis is performed in order to understand the response for different earthquake directions, as well as to explore the effect of frequency content of the earthquake.

\subsection{The direction of the earthquake}

The vertical component of the earthquake has less effect on the structure, due to the safety margins against the static gravity acceleration. However the peak vertical acceleration is often assumed to be $2 / 3$ of the peak horizontal acceleration (Wilson [12]). To study the earthquake component in horizontal plane, two principle directions can be considered. The first is associated with the structure 'The principle direction of the structure' and indicates the weakest direction of the structure, and the other is associated with the earthquake 'the principle direction of the earthquake' and corresponds to the direction at which the horizontal ground acceleration amplifies the maximum. The worst case occurs when the principle direction of the structure and the earthquake are identical. 

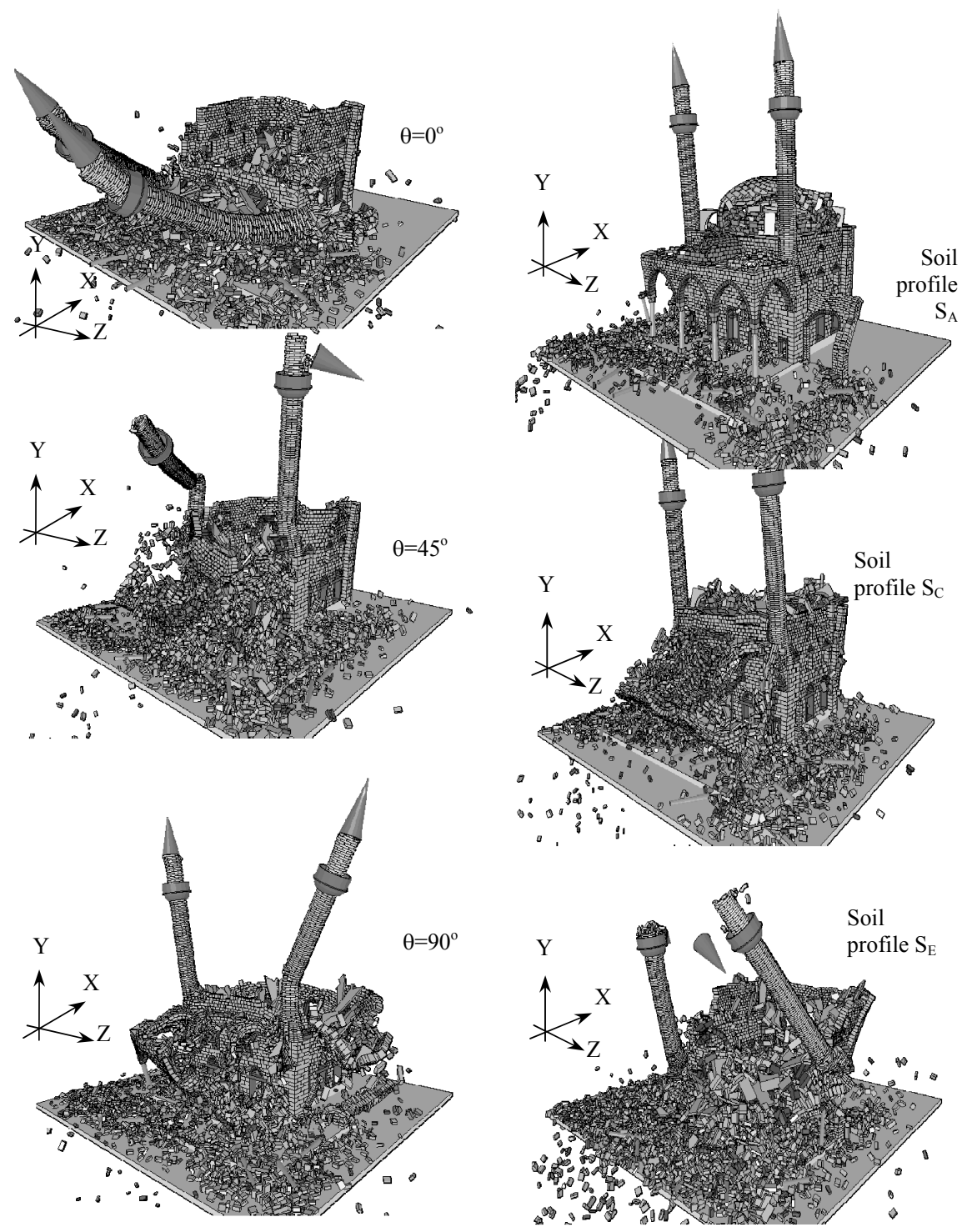

Figure 5: The collapse states of the structure for different earthquake angels at time 9 seconds (right), for different soil profiles at time 7 seconds (left).

Due to the uncertainties in earthquake direction and in order to get well assessment, the structure should be capable of equally resisting earthquake motions from all possible directions. In some of the existing engineering's standards the structure should be assessed for " $100 \%$ of the prescribed seismic forces in one direction plus $30-40 \%$ of the prescribed forces in the perpendicular 
direction" (Wilson [12]). However, no suggestions are given on how the directions have to be determined for complex structures. In order to understand the collapse behaviour of the structure for different earthquake directions, the same generated accelerogram has been applied on the structure in the horizontal plane, for different angels with respect to $\mathrm{x}$ axis, namely: $\theta=0^{\circ}, 45^{\circ}$ and $90^{\circ}$. Figure 5, shows the collapse states of the structure which corresponds to the angels of $\theta=0^{\circ}, 45^{\circ}$ and $90^{\circ}$ after 9 seconds of the initiation of earthquake. It is quite evident that the weakest case of the structure corresponds to $\theta=0^{\circ}$, where at this angel, the earthquake is much destructive than other directions.

\subsection{The frequency content of the earthquake}

The earthquake actions span a broad range of frequencies. The frequency content describes how the amplitude of the ground motion is distributed among different frequencies. The well description of this relation for an earthquake can be obtained from the corresponding response spectrum.

Due to the significant influence of frequency content of the earthquake ground motion on the structure, it has been subjected to different earthquakes with different frequency contents. The geological properties of the site are highly influencing the frequency content of the earthquake motion that the structure receives. Therefore, three earthquake motions were generated for different soil profiles, namely: $\mathrm{S}_{\mathrm{A}}, \mathrm{S}_{\mathrm{C}}$ and $\mathrm{S}_{\mathrm{E}}$, Figure 6 . The aim of considering several soil profiles in this study is to understand the influence of the site characteristics on the collapse behaviour of the structure. Furthermore, many structures in several countries have the similar architecture of the mosque of Takiyya alSulaymaniyya. Figure 5 shows the collapse states of the structure which

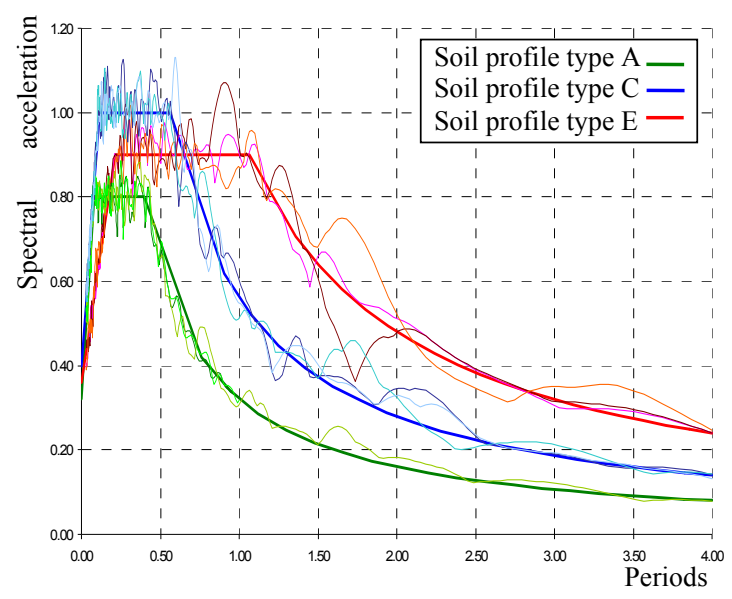

Figure 6: Response spectra for different soil types $\mathrm{A}, \mathrm{C}$ and $\mathrm{E}$ for $\mathrm{Z}=0.4$, the thick lines are the original response spectra, whereas the thin lines refer to the response spectra of the generated accelerograms. 
corresponds to the soil profiles $\mathrm{S}_{\mathrm{A}}, \mathrm{S}_{\mathrm{C}}$ and $\mathrm{S}_{\mathrm{E}}$ after 7 seconds. It is quite evident that the weakest case of the structure corresponds to the soft soil profile $S_{E}$, where for this site conditions, the earthquake is much destructive.

\section{Concluding remarks future research aspects}

Historical masonry structures which comprise different type of structural members result in different responses and therefore different collapse mechanisms. The interactions between those members are of high importance for the whole response of the structure. For the historical structure in this study, the relatively high deformations of the pendentives are the major reason for the collapse of the dome.

Collapse analysis of the structure under unidirectional earthquake actions is performed, to explore the weakest direction of the structure. However, the formulation of the mechanical behaviour is not covered in this paper, and it is very appropriate to employ the described methodology as a tool for further research in this direction. The present study shows that, the earthquakes in regions of soft soils are more destroyable to the structure, but the soft soils dissipate a great amount of the kinetic energy that cased by earthquake. Furthermore, the other phenomena that might occur due to the failure of soil and liquefaction should be considered for more detailed study.

\section{References}

[1] Aagaard, B.T.: Finite-Element Simulations of Earthquakes. PhD-Thesis, California Institute of Technology, 2000.: Pasadena, California 2000

[2] Bala, S.: Tie-Break Contacts in LS-DYNA. Livemore Software. USA 2007

[3] Croci, G.: Seismic Behaviour of Masonry Domes and Vaults Hagia Sophia in Istanbul and St. Francis in Assisi. In: Proc. of the $1^{\text {st }}$ European Conference on Earthquake Engineering and Seismology: Geneva, Switzerland 2006

[4] Hallquist, J.O.: LS-DYNA Theory Manual, Livemore Software Technology Corporation: California, USA 2005

[5] Malkawi, A.H.; Liang, R.Y.; Nusairat, J.H. \& Al-Hamoud, A.S.: Probabilistic Seismic Hazard Zonation of Syria. Natural Hazards, 12 , pp. 139-151, 1995

[6] Meskouris, K.: Structural Dynamics, Models, Methods, Examples, Ernst \& Sohn: Berlin 2000

[7] Rihawi, A.: Arabic Islamic Architecture in Syria. Damascus, Ministry of Culture and National Heritage: Syria 1979

[8] Rofooei, F.R.; Mobarake, A. \& Ahmadi, G.: Generation of Artificial Earthquake Records with a Nonstationary Kanai-Tajimi model. Engineering Structures, 23 (7), pp. 827-837, 2001

[9] Sbeinati, M.R.; Darawcheh, R. \& Mouty, M.: The Historical Earthquakes of Syria: and analysis of large and moderate earthquakes from 1365 B.C. to 1900 A.D. Annals of Geophysics, 48 (3), pp. 347-435, 2005 
394 Structural Studies, Repairs and Maintenance of Heritage Architecture XI

[10] Thiele, M.: Spectrum Compatible Accelerograms in Earthquake Engineering. Universidad de La Serena, Chile and Technische Universität Dresden: Dresden 2002

[11] UBC97: 1997: Uniform Building Code, Vol.2. International Code Council: USA 1997

[12] Wilson, E.L.: Three-Dimensional Static and Dynamic Analysis of Structures- Third Edition, Computers and Structures, Inc.: Berkeley, California, USA 2002 